\title{
Tulane
}

Tulane Economics Working Paper Series

\section{Incidental Emotions, Integral Emotions, and Decisions to Pay Taxes}

\author{
Janina Enachescu \\ University of Vienna \\ janina.enachescu@univie.ac.at \\ Jerome Olsen \\ University of Vienna
}

.

\author{
Žiga Puklavec \\ University of Vienna \\ Erich Kirchler \\ University of Vienna \\ erich.kirchler@univie.ac.at
}

\author{
Christian Martin Bauer \\ University of Vienna \\ James Alm \\ Tulane University
}

Working Paper 1909

October 2019

\begin{abstract}
In this paper we present initial investigations of the role of emotions on tax compliance decisions. We first introduce selected emotion theories, and we also present different paths by which emotions can possibly affect tax decisions, namely indirectly via mood and emotions unrelated to the tax decision itself (or "incidental emotions") and directly via emotions that are elicited in the taxation context itself (or "integral emotions"). We then present and discuss an experimental study investigating the first path suggested above, the influence of positive versus negative mood on tax compliance. Further, we also present and analyze a study exploring emotions elicited by the taxation context. Finally, we suggest that a fruitful path for future research is the integration of emotions into the slippery slope framework of tax compliance.
\end{abstract}

Keywords: Tax compliance, incidental emotions, integral emotions, behavioal economics, nudges, laboratory experiments.

JEL codes: H26, C91. 


\title{
Incidental Emotions, Integral Emotions, and Decisions to Pay Taxes
}

\author{
Janina Enachescu ${ }^{1}$, Žiga Puklavec ${ }^{1}$, Christian Martin Bauer ${ }^{1}$, \\ Jerome Olsen ${ }^{1}$, Erich Kirchler ${ }^{1}$, and James Alm ${ }^{2}$
}

\begin{abstract}
:
In this paper we present initial investigations of the role of emotions on tax compliance decisions. We first introduce selected emotion theories, and we also present different paths by which emotions can possibly affect tax decisions, namely indirectly via mood and emotions unrelated to the tax decision itself (or "incidental emotions") and directly via emotions that are elicited in the taxation context itself (or "integral emotions"). We then present and discuss an experimental study investigating the first path suggested above, the influence of positive versus negative mood on tax compliance. Further, we also present and analyze a study exploring emotions elicited by the taxation context. Finally, we suggest that a fruitful path for future research is the integration of emotions into the slippery slope framework of tax compliance.
\end{abstract}

KEYWORDS: Tax compliance, incidental emotions, integral emotions, behavioal economics, nudges, laboratory experiments.

JEL CODES: H26, C91.

Acknowledgement: We thank the students of the seminars on theory and empirical research in economic psychology at the Faculty of Psychology, University of Vienna, Austria, for their assistance in conducting the laboratory experiments.

${ }^{1}$ University of Vienna, Faculty of Psychology, Universitaetsstrasse 7, A-1010 Vienna, Austria.

${ }^{2}$ Tulane University

Corresponding authors: Janina Enachescu (Email: janina.enachescu@univie.ac.at) and Erich Kirchler (Email: erich.kirchler@univie.ac.at) 


\section{$\underline{\text { 1. Introduction }}$}

Decisions to pay or to evade taxes are frequently seen as decisions under uncertainty. According to expected utility theory, taxpayers are motivated to maximize their own profit by rationally considering payoffs of compliance and non-compliance, balancing the gain from underreporting income against the loss from detection and unpunishment.

This perspective is formalized in the economics of crime paradigm of Becker (1962), Allingham \& Sandmo (1972), and Srinivasan (1973). In their analyses, the audit probability, the fine rate, and the tax rate combine with the taxpayer's income and attitude toward risk as the main determinants of compliance. They typically propose frequent audits and severe fines as the policy tools to enforce compliance. These seminal theoretical publications have fueled intense empirical work, and there are now many empirical studies on the impact of audits and fines on compliance. However, the emphasis on these financial factors is somewhat ironic, given Allingham \& Sandmo's (1972) explicit statement that their theory

“...may perhaps be criticized for giving too little attention to nonpecuniary factors in the taxpayer's decision on whether or not to evade taxes. It need hardly be stressed that in addition to the income loss there may be other factors affecting utility if one's attempt at tax evasion is detected. These factors may perhaps be summarily characterized as affecting adversely one's reputation as a citizen of the community..." (p. 326).

Indeed, numerous psychological studies show that in complex decision situations people hardly behave according to expected utility theory. Instead, people are hardly likely to consider all potentially relevant aspects of a decision. Limited processing capabilities foster the use of heuristics, and an individual's risk behavior is affected by the framing of the decision situation (Kahneman, 2003).

In addition, there is increasing evidence that emotions affect judgements, decisions, and behavior (e.g. Lerner, Li, Valdesolo, \& Kassam, 2015). Despite the existence of many studies that have examined various socio-psychological factors in tax compliance decisions (Kirchler, 2007), the impact of emotions on tax compliance decision has been mostly neglected, with some notable exceptions (Coricelli, Joffily, Montmarquette, \& Villeval, 2010; Murphy \& Tyler, 2008).

We want to emphasize that the relative lack of research on emotions in tax compliance research can hardly be attributed to the origins of the rational choice paradigm. Elffers (2015) notes that many of the founding fathers of rational choice were well aware of the potential importance of emotions. He writes that "Dirck Coornhert, Adam Smith, and Jeremy Bentham introduced in their original writings their perspectives in terms of norms, guilt, conscience, 
pity and other affects... When considering Smith's work, even the title of his treatise, The Theory of Moral Sentiments (Smith 1759/1982), is an illustration of the point" (Elffers, 2015, p. 53). Nonetheless, the importance of emotions in decision making has been largely neglected in many empirical research fields for a long time (Elster, 1998).

In this paper we present initial investigations of the role of emotions on tax compliance decisions. We first introduce selected emotion theories, and we also present different paths by which emotions can possibly affect tax decisions, namely indirectly via mood and emotions unrelated to the tax decision itself (or "incidental emotions") and directly via emotions that are elicited in the taxation context itself (or "integral emotions"). We then present and discuss an experimental study investigating the first path suggested above, the influence of positive versus negative mood on tax compliance. Further, we also present and analyze a study exploring emotions elicited by the taxation context. Finally, we suggest that a fruitful path for future research is the integration of emotions into the slippery slope framework of tax compliance (Kirchler, 2007).

\section{What are emotions?}

Traditionally, cognitive processes and decision making have been studied without considering affect, mood, and emotions (Loewenstein, 2000). Decisions were assumed to result from the individual evaluation of expected consequences of alternatives. Out of a set of alternatives, people should choose the alternative with the greatest and most likely positive consequences (Loewenstein \& Lerner, 2003). In this tradition, emotions did not receive much attention. However, social psychologists have increasingly pointed to the importance of affect, positive and negative mood, and the quality of emotions in cognitive processes and decision making (e.g. Forgas, 1995; Lerner et al., 2015; Schwarz, 2012). Here we discuss this research, in order to lay the foundation for our subsequent discussion.

Most people have an instinctive understanding of what emotions are. However, in psychological theory, emotions are considered complex phenomena, and researchers are far from agreeing on a precise definition. Most generally, emotions are states of feelings accompanied by physical and psychological changes that affect behavior. Emotions are subjective and conscious experiences that are characterized by psycho-physiological reactions to biological states, mental states, and interpretations of the situations experiences, or objects. Emotions are also connected to motivational and behavioral intentions. For theoretical clarity, 
we need to distinguish emotions that are acute, intense, and object-related (Zeelenberg \& Pieters, 2006), from the more generic term "mood" that refers to less intense and more durable affective states that are not triggered by a specific event (Scherer, 2005).

Regarding the composition of emotions, Scherer (2005) distinguishes cognitive appraisal, bodily symptoms, action tendencies, expressions, and feelings in his components processing model. Cognitive appraisal refers to evaluations of events. Bodily symptoms indicate the psycho-physiological component of emotions. Action tendencies refer to the motivational aspects of emotions. Expressions are facial and vocal expressions that accompany emotions, and feelings indicate the subjective experience of an emotional state.

Some researchers have proposed specific definitions of emotions. For example, Fehr and Russel (1984) asked people what comes readily to their mind when thinking about emotions, and they found that happiness, anger, sadness, love, fear, hate, and joy were the most often-mentioned qualities of emotions. Izard (1977) defined a list of basic emotions including interest, joy, surprise, distress, anger, fear, shame, disgust, contempt, and guilt. These qualities of emotions are prototypical for categories of emotions. Indeed, the number of categories varies across research, and categories are generally fuzzy. Various scholars agree to organize emotion categories along one or more dimensions. For example, the positivenegative affect scale (PANAS) is an instrument developed to assess affect, based on the assumption that emotions can be categorized along the valence dimension (Watson, Clark, \& Tellegen, 1988). Other models organize distinct emotions along the dimensions valence and activation on a circumplex structure (Russell \& Barrett, 1999). Turner and Stets (2005) distinguish between three basic dimensions of emotions: arousal indicates the intensity of emotions, valence indicates whether emotions are positive or negative, and potency expresses whether an individual feels strong or weak when experiencing a specific emotion.

Scherer (2005) developed the "Geneva Emotions Wheel", which distinguishes between twenty emotion qualities that vary from negative to positive valence and from low to high control or power (Figure 1). Sacharin, Schlegel, and Scherer (2012) write that the Geneva Emotions Wheel

“... consists of discrete emotion terms corresponding to emotion families that are systematically aligned in a circle. Underlying the alignment of the emotion terms are the two dimensions valence (negative to positive) and control (low to high), separating the emotions in four quadrants: Negative/low control, negative/high control, positive/low control, and positive/high control. Note that the control dimension is also called control/power [...]. The response options are 'spikes' in the wheel that correspond to different levels of intensity for each emotion family from low intensity 
(towards the center of wheel) to high intensity (toward the circumference of the wheel). Also, in the very center of the wheel, the response options 'no emotion' and 'other emotion' is offered." [accessed January 15 2019].

\section{Figure 1: Geneva Emotion Wheel}

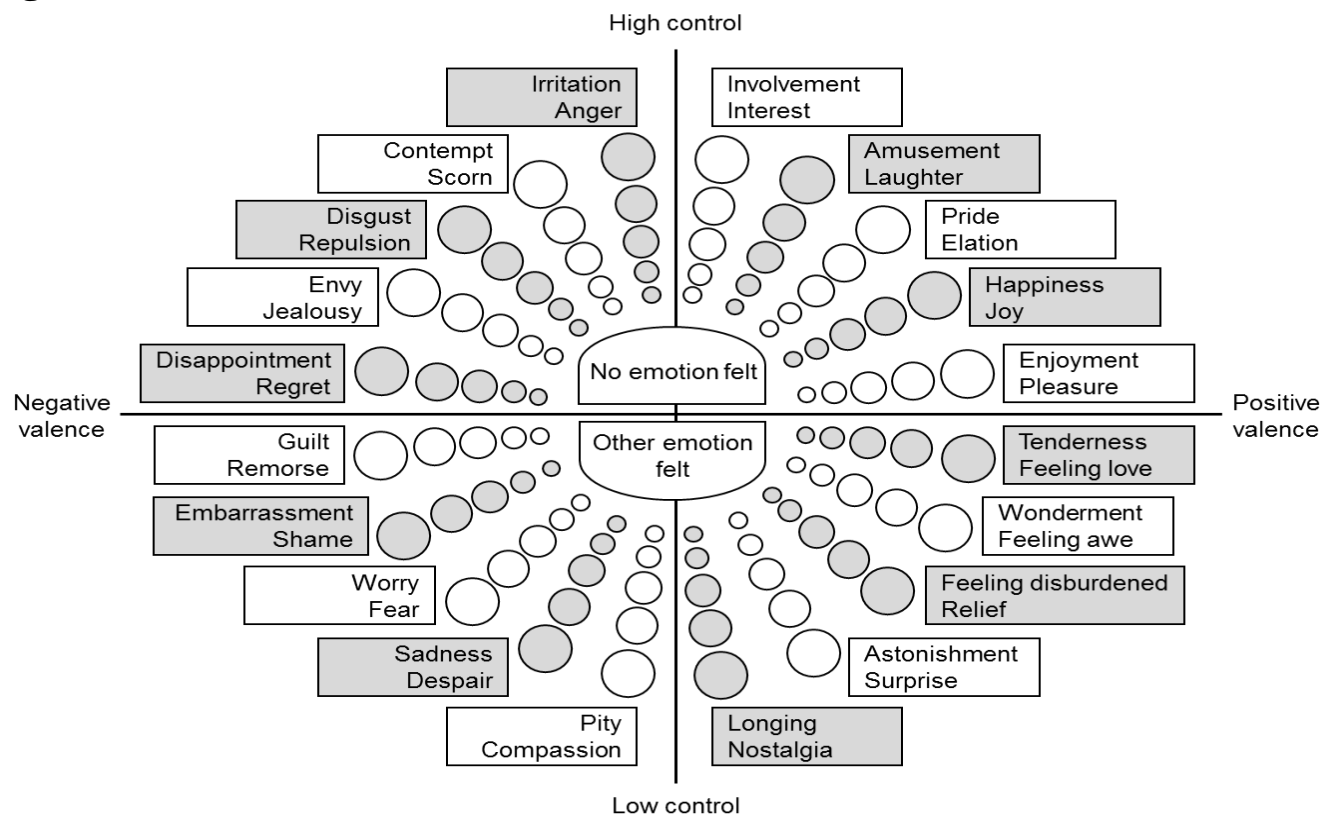

Notes: Figure 1 is adapted from Sacharin, Schlegel, and Scherer (2012).

In contrast to these dimensional approaches, other scholars emphasize the importance of looking at specific emotions, when interested in behavioral consequences. Anger and fear, for instance, are two emotions of comparable negative valence that can have the same level of arousal but that are associated with different judgments and behavioral consequences (Lerner \& Keltner, 2000). Anger is typically associated with fight, whereas fear tends to evoke flight. With regard to these behavioral consequences, it is therefore important to consider specific emotions rather than following a dimensional approach. Zeelenberg and Pieters (2006) propose the feeling-is-for-doing approach to emotions, emphasizing the need to investigate the role of specific emotions and to focus on the motivational component of emotions, an approach that they term "emotivation".

\section{$\underline{\text { 3. How do emotions influence decisions? }}$}

Loewenstein and Lerner (2003) developed a framework that illustrates the different paths by which emotions can influence decision making processes. They distinguish between 
the influence of "anticipated" versus "immediate" emotions. For instance, taxpayers considering evading taxes may refrain from doing so because they anticipate regret in case of being caught and facing a severe fine or loss of reputation. Erard and Feinstein (1994) assume that shame and guilt are such "anticipated" moral costs of tax evasion when thinking about the possible consequences of honestly declaring income versus dishonestly cheating on one's declaration. The importance of such moral costs has been stressed by multiple authors (Blaufus, Bob, Otto, \& Wolf, 2017; Bosco \& Mittone, 1997; Grasmick \& Bursik, 1990). People choose alternatives that are likely to elicit positive emotions, they try to avoid future regrets from not having chosen an alternative, and they avoid alternatives that are likely to cause negative feelings (van de Ven \& Zeelenberg, 2011).

Besides anticipated emotions, emotions can be experienced immediately at the time of decision making. An especially important distinction here is between "incidental" and "integral" emotions. Incidental emotions are not related to the decision context itself but arise from surrounding circumstances. For example, sunny weather can make one feel happy, and this emotion can influence information processing as well as judgments and decision making (Schwarz, 2012). In contrast, integral emotions stem directly from the decision situation. For instance, consumer research shows that poor service quality can trigger anger, which in turn influences subsequent consumer decisions (Bougie, Pieters, \& Zeelenberg, 2003).

These distinctions suggest that a taxpayer's compliance decision might vary with emotions elicited during communications with the tax authorities or with frustration triggered by complexity when filing a tax declaration. The different paths of emotional influences on decision-making are illustrated in Figure 2.

Figure 2: Determinants and consequences of immediate and expected emotions

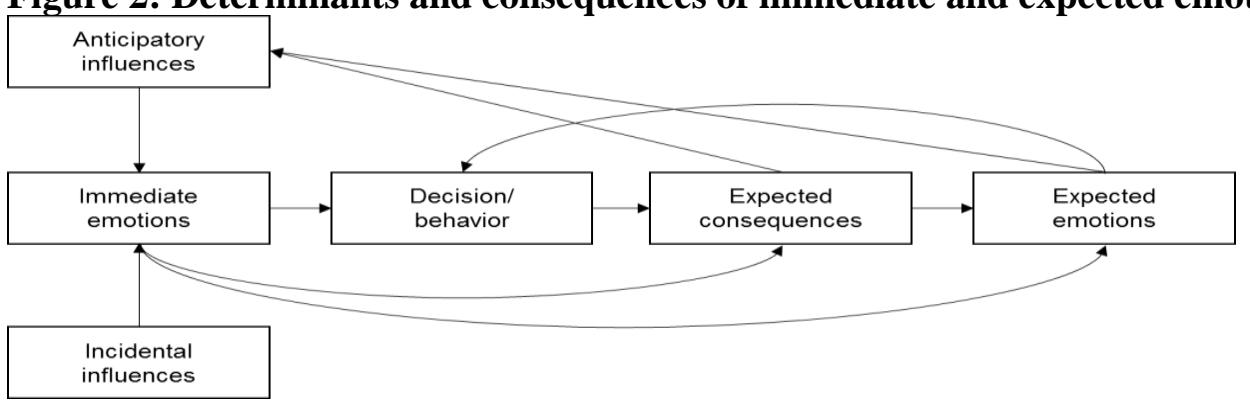

Notes: Figure 2 is adapted from Loewenstein and Lerner (2003, p. 621). 
One example for research on incidental emotions is a study by Drouvelis and Grosskopf (2016), who investigated the impact of emotions on cooperation and sanctioning behavior in a laboratory contribution game. Anger and happiness were induced by presenting short video clips to participants before they had to make contribution decisions. Drouvelis and Grosskopf (2016), found that participants in the angry condition contributed significantly less than those in the happy condition, and that participants also tended to punish their counterparts more harshly than participants who were in a happy emotional state.

As for integral emotions, Coricelli et al. (2010) measured participants' arousal levels in a standard laboratory income-reporting game. Participants were endowed with a fixed income, and they decided how much to report to the authorities. If caught underreporting, they had to pay a fine. However, in addition to the payment of the fine, participants who were detected cheating had their portrait publicly displayed. This experimental design therefore allowed Coricelli et al. (2010) to investigate the impact on compliance of the emotional costs of shaming people for tax evasion. The results showed that the intensity of experienced emotions is positively related to tax evasion.

In another laboratory study, Dulleck et al. (2016) measured heart rate variability (or psychic stress), as an indicator for moral sentiments, during a public goods game. Participants were either endowed with a fixed amount of income in each round or they earned money according to performance in a cognitive skills task. Dulleck et al. (2016) examined how the heart rate variability varied as participants made tax payment decision. Contrary to Coricelli et al. (2010), Dulleck et al. (2016) found a positive relation between arousal and tax compliance. While the differentiated impact of specific emotions on tax compliance remains unclear, these two studies emphasize the importance of emotional experiences for taxation.

In another study, Olsen et al. (2018) conducted an experimental survey with real selfemployed taxpayers in Turkey. They found that taxpayers reported different emotions in response to the tax authorities' enforcement strategies. When the tax authorities focus on harsh enforcement methods, such as audits and fines, negative emotions, which are related to increased readiness to evade taxes, are evoked. However, when the tax authorities emphasize service that facilitates the payment of taxes, together with a trusting relationship between tax authorities and taxpayers, negative emotions are reduced, and intentions to comply with the tax law are promoted.

Fochmann, Hechtner, and Mohr (2019) conducted two laboratory experiments testing the effect of incidental emotions on compliance behavior. They induced (or primed) both 
positive and negative emotions using pictures, which were intended to evoke either positive (e.g., a mother with a baby) or negative (e.g., a garbage dump) feelings. They found that individuals are less willing to comply after being primed with positive incidental emotions as compared to being primed with negative emotions. These results were especially true if individuals described themselves as sensitive to emotion-eliciting information. However, before concluding that positive incidental emotions lead to less compliance than negative emotions, the specific nature of the induced emotions should be considered. For example, while fun may affect behavior in one way, pride may have different effects. Similarly, anger and fear - both negative emotions - are likely to have different impacts on decisions.

These studies have made considerable contributions to our understanding of the potential role of emotions in taxpayer decisions. They all demonstrate that emotional experiences may affect taxpayer behavior. However, they also demonstrate that the impact of emotional experiences on taxpayer behavior is an unresolved issue. In the next sections, we discuss several studies of our own that attempt to advance our understanding of this issue.

\section{Empirical study (1): Incidental emotions and tax compliance}

To further study the effect of incidental emotions on tax compliance, we conducted an incentivized laboratory tax experiment where mood was induced using background music. The experimental design comprised three between-subject conditions: a positive mood condition with background music by Wolfgang Amadeus Mozart, a negative mood condition with background music by Gustav Holst, and a control condition without any background music.

Emotions tend to guide our attention and to serve as indicators for pain or pleasure (Pfister \& Böhm, 2008). According to the feelings-as-information theory, we rely on affective information when evaluating our environment and making judgments. While neutral or positive feelings are the status quo, negative feelings signal the presence of problems that require an explanation and elevated attention (Schwarz, 2012). Therefore, people tend to

process information more thoroughly and systematically when they are in a negative mood as compared to a neutral mood. On the other hand, a positive mood is associated with heuristic information processing and the reliance on stereotypes. In line with the feelings-asinformation theory background, we assumed that participants in the negative condition are 
likely to evade more taxes than those in the positive condition. Note that evading is assumed to be the rational strategy given the audit and fine parameters in our experiment.

Previous research suggests that background music is a promising method to induce positive or negative mood (Garlin \& Owen, 2006; Kämpfe, Sedlmeier, \& Renkewitz, 2011; Martin, 1990; White \& Rickard, 2016). For instance, Thompson, Schellenberg, \& Husain (2001) found that playing a piece by Wolfgang Amadeus Mozart induced high arousal and positive mood in subjects, while subjects exhibited low arousal and sad mood after listening to a piece composed by Tomaso Albinoni (Thompson et al., 2001).

\subsection{Method}

Sample: Overall, 123 subjects participated in the experiment. Most participants were students of social sciences, with an average age of 24.7 years. $57.7 \%$ of the participants were female. Table 1 displays detailed socio-demographic information by experimental conditions.

Table 1: Sample socio-demographic statistics

\begin{tabular}{|c|c|c|c|c|}
\hline & $\begin{array}{r}\text { Control } \\
\text { condition }\end{array}$ & $\begin{array}{r}\text { Positive mood } \\
\text { condition } \\
\end{array}$ & $\begin{array}{r}\text { Negative mood } \\
\text { condition }\end{array}$ & Total \\
\hline $\mathrm{N}$ & 41 & 41 & 41 & 123 \\
\hline Female $(\%)$ & $\begin{array}{r}26 \\
(63.4 \%)\end{array}$ & $\begin{array}{r}22 \\
(53.7 \%)\end{array}$ & $\begin{array}{r}23 \\
(56.1 \%)\end{array}$ & $\begin{array}{r}71 \\
(57.7 \%)\end{array}$ \\
\hline Mean age (SD) & $\begin{array}{r}23.95 \\
(4.34)\end{array}$ & $\begin{array}{l}25.68 \\
(6.08)\end{array}$ & $\begin{array}{r}24.51 \\
(4.87)\end{array}$ & $\begin{array}{r}24.72 \\
(5.16)\end{array}$ \\
\hline Student $(\%)$ & $\begin{array}{r}39 \\
(94.3 \%) \\
\end{array}$ & $\begin{array}{r}38 \\
(92.7 \%) \\
\end{array}$ & $\begin{array}{r}39 \\
(95.1 \%) \\
\end{array}$ & $\begin{array}{r}116 \\
(94.3 \%) \\
\end{array}$ \\
\hline \multicolumn{5}{|l|}{ Employment status } \\
\hline Unemployed (\%) & $\begin{array}{r}20 \\
(48.8 \%)\end{array}$ & $\begin{array}{r}17 \\
(41.5 \%)\end{array}$ & $\begin{array}{r}16 \\
(39.0 \%)\end{array}$ & $\begin{array}{r}53 \\
(43.1 \%)\end{array}$ \\
\hline Marginally employed (\%) & $\begin{array}{r}12 \\
(29.3 \%)\end{array}$ & $\begin{array}{r}16 \\
(39.0 \%)\end{array}$ & $\begin{array}{r}13 \\
(31.7 \%)\end{array}$ & $\begin{array}{r}41 \\
(33.3 \%)\end{array}$ \\
\hline Part-time employed (\%) & $\begin{array}{r}7 \\
(17.1 \%)\end{array}$ & $\begin{array}{r}7 \\
(17.1 \%)\end{array}$ & $\begin{array}{r}6 \\
(14.6 \%)\end{array}$ & $\begin{array}{r}20 \\
(16.3 \%)\end{array}$ \\
\hline Full-time employed (\%) & $\begin{array}{r}2 \\
(4.9 \%) \\
\end{array}$ & $\begin{array}{r}1 \\
(2.4 \%) \\
\end{array}$ & $\begin{array}{r}6 \\
(14.6 \%) \\
\end{array}$ & $\begin{array}{r}9 \\
(7.3 \%) \\
\end{array}$ \\
\hline \multicolumn{5}{|l|}{ Type of work } \\
\hline No-employment (\%) & $\begin{array}{r}21 \\
(51.2 \%)\end{array}$ & $\begin{array}{r}16 \\
(39.0 \%)\end{array}$ & $\begin{array}{r}19 \\
(46.3 \%)\end{array}$ & $\begin{array}{r}56 \\
(45.5 \%)\end{array}$ \\
\hline Blue collar worker (\%) & $\begin{array}{r}3 \\
(7.3 \%)\end{array}$ & $3(7.3 \%)$ & $4(9.8 \%)$ & $\begin{array}{r}10 \\
(8.1 \%)\end{array}$ \\
\hline White collar worker $(\%)$ & $\begin{array}{r}16 \\
(39.0 \%)\end{array}$ & $\begin{array}{r}18 \\
(43.9 \%)\end{array}$ & $\begin{array}{r}14 \\
(34.1 \%)\end{array}$ & $\begin{array}{r}48 \\
(39.0 \%)\end{array}$ \\
\hline Self-employed (\%) & $\begin{array}{r}1 \\
(2.4 \%)\end{array}$ & $\begin{array}{r}4 \\
(9.8 \%)\end{array}$ & $\begin{array}{r}4 \\
(9.8 \%)\end{array}$ & $\begin{array}{r}9 \\
(7.3 \%) \\
\end{array}$ \\
\hline
\end{tabular}


Method and Procedure: The experiment took place in the Social Science Research Lab at the Faculty of Psychology, University of Vienna. Participants were randomly assigned to one of three between-subject conditions; i.e., positive mood, negative mood, and control. In the two mood conditions, a recording was played in the adjacent room. The wall between the two rooms was thin and noise-permeable. When participants arrived in the lab, the recording started with two people softly leading a discussion. The volume was adjusted so that participants would not hear what was being said, but would know that there were sounds in the adjacent room. After all participants were seated in one of the cubicles and the verbal instructions by the experimenter were finished, the recorded discussion ended and music started to play. The music was played loud enough so that it was very likely for everyone to hear the song. The nature of the music was not explained to participants in any way.

In the positive mood condition, Wolfgang Amadeus Mozart's "Sonata for Two Pianos in D Major, KV 448" was played. In the negative mood condition, Gustav Holt's "The Planets, Mars, The Bringer of War" was played (Baumgartner, Esslen, \& Jäncke, 2006; Thompson et al., 2001). In the control condition, the recording of the two-people discussion ended at the beginning of the experiment and no music was played.

The actual experimental task consisted of an income reporting tax game (Figure 3). The experiment started with two test rounds, followed by twelve actual decision rounds. In each round participants were endowed with a base income of $1000 \mathrm{ECU}$ and could additionally earn up to 1000 ECU according to their performance in a real-effort slider task (Gill \& Prowse, 2012). The effort task consisted of ten sliders per round, which participants had to move exactly to their center point. For each correctly solved slider, participants received 100 ECU additional income. Hence, a maximum income of 2000 ECU per round was possible.

After each round, participants had to declare the amount of taxes they wanted to pay. The tax rate was fixed at $40 \%$, and there was an audit probability of $25 \%$. To keep audit sequence effects constant across conditions, audits were pre-determined to occur in three of the twelve rounds, or rounds four, six, and eleven. In case of detected evasion, participants had to pay the evaded amount of taxes plus a fine of the same size. Participants were not informed about the number of rounds to be played. At the end of the experiment participants received remuneration according to their income in one randomly selected round (1 Euro = $300 \mathrm{ECU})$.

After playing the tax game, participants were asked to indicate their current affective state on the Geneva Emotions Wheel (Scherer, 2005), as presented in Figure 1. This measure 
served as a manipulation check to see whether exposure to different music or to no music lead to the expected changes in positive and negative mood. The experiment concluded with basic socio-demographic questions.

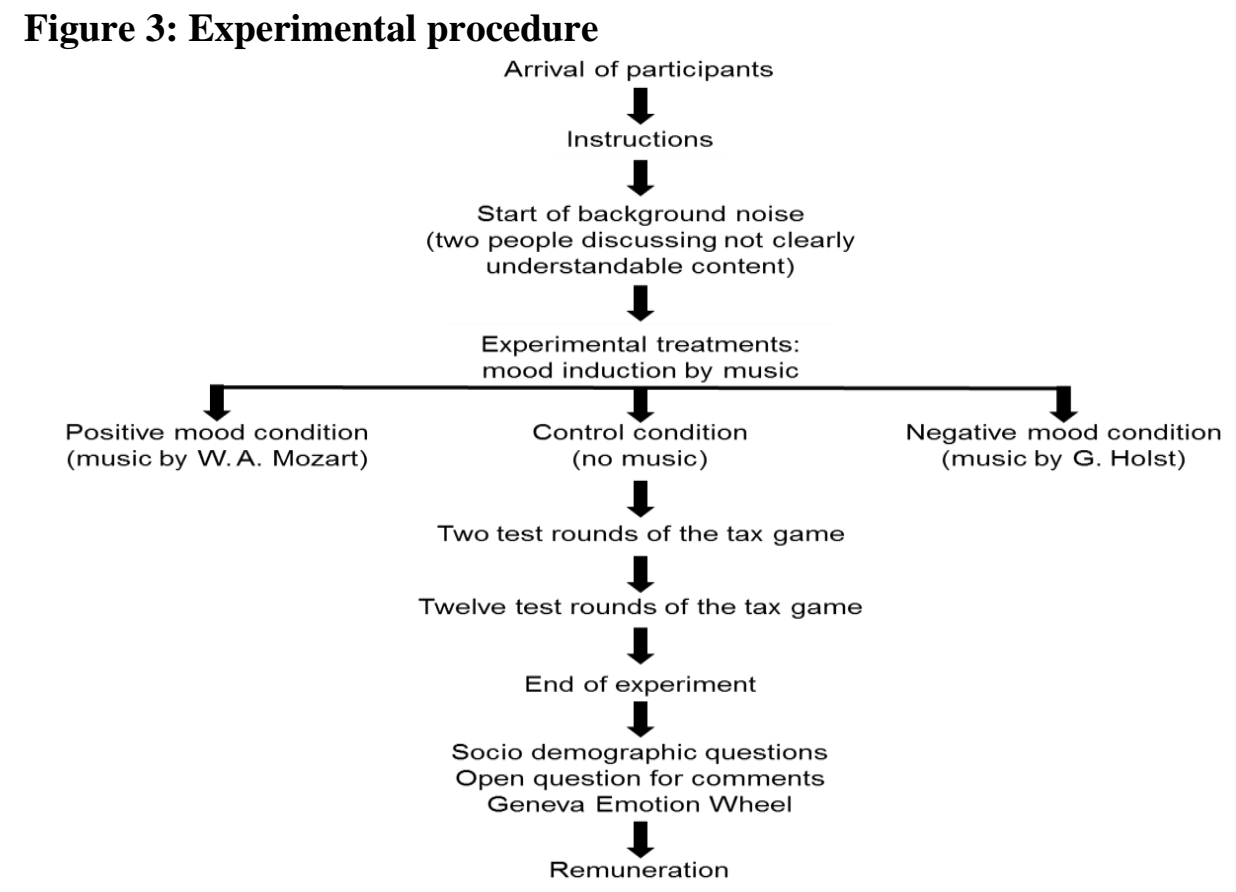

\subsection{Results}

We first report the results of the manipulation check of the mood induction, followed by results on the effects of mood on tax compliance. We also explore whether the audit outcome affected participants' moods.

Manipulation check. In order to check whether the manipulation of positive and negative mood was successful, we first aggregated the single emotion scores of all positive emotions to one positive mood score, and analogously all negative emotions to one negative mood score. See Table 2 for descriptive statistics.

Table 2: Positive and negative mood scores by condition

\begin{tabular}{lccc}
\hline & $\begin{array}{c}\text { Positive mood } \\
\text { condition }\end{array}$ & $\begin{array}{c}\text { Negative mood } \\
\text { condition }\end{array}$ & $\begin{array}{c}\text { Control } \\
\text { condition }\end{array}$ \\
\hline Positive mood Mean (SD) & $5.34(1.12)$ & $5.33(0.78)$ & $5.20(1.07)$ \\
Negative mood Mean (SD) & $4.01(1.23)$ & $4.07(1.06)$ & $3.90(1.31)$ \\
\hline
\end{tabular}


We then ran two separate regression models with the positive and negative mood scores as the respective outcome variable. The condition variable was entered as predictor. Results revealed no significant effect of condition, neither for the positive mood score nor for the negative mood score. For detailed regression results, see Table 3.

Table 3: Manipulation check regression models for positive and negative mood scores

\begin{tabular}{lccccccc}
\hline & \multicolumn{3}{c}{ Positive mood score } & & \multicolumn{3}{c}{ Negative mood score } \\
\cline { 2 - 4 } \cline { 7 - 9 } & $\boldsymbol{B}$ & $\boldsymbol{S E}$ & $\boldsymbol{p}$ & & $\boldsymbol{B}$ & $\boldsymbol{S E}$ & $\boldsymbol{p}$ \\
\hline Intercept & 5.20 & 0.16 & $<.001$ & & 3.90 & 0.21 & $<.001$ \\
Positive condition & 0.14 & 0.23 & .541 & & 0.12 & 0.30 & .706 \\
Negative condition & 0.13 & 0.22 & .560 & & 0.17 & 0.29 & .557 \\
\hline & & & & & & & \\
Intercept & 5.34 & 0.16 & $<.001$ & & 4.01 & 0.22 & $<.001$ \\
Control condition & -0.14 & 0.23 & .541 & & -0.12 & 0.30 & .706 \\
Negative condition & -0.01 & 0.23 & .971 & & 0.06 & 0.30 & .554 \\
\hline
\end{tabular}

Notes. $N_{\text {pos }}=118, \mathrm{~N}_{\mathrm{neg}}=98$. The variable condition had three levels with positive condition, negative condition, and control condition. We ran each regression twice, changing the dummy coding to see all possible condition comparisons. In the top models, the control condition was set as the reference category; in the lower models, the positive condition served as reference group.

Manipulation of mood by music also did not have a significant effect on specific emotion qualities. We conducted a linear mixed model with a random intercept for participants to account for the repeated measures structure of the data, predicting 20 specific emotion scores by condition. We found no significant overall effect of condition on the emotion scores when comparing the positive condition against the control condition $(b=0.15$, $p=0.524$ ). We also found no significant overall effect of condition on the emotion scores when comparing the negative condition against the control condition $(b=0.19, p=0.422)$. The results did not change when we changed the reference category from the control condition to the positive condition.

Effect of mood on tax compliance. Irrespective of the failed manipulation, we conducted a linear mixed model with relative tax compliance in each round as outcome variable (equal to paid tax / tax due) and condition as predictor. The predictor was dummy coded with the control condition as reference category. The model specified a random intercept for individuals, thereby controlling for the repeated measures data structure. The effect of the conditions on tax compliance across the twelve rounds of the tax game revealed a significant 
difference in tax compliance between the control condition and the positive mood condition $(b=0.16, p=0.018)$. However, there was no significant difference between the control condition and the negative mood condition. $(b=0.07, p=0.309)$. Changing the reference category revealed no significant difference between the positive and negative mood condition $(b=0.09, p=0.170)$. Figure 4 illustrates relative tax compliance for all twelve rounds by condition. Note that the sharp drops in compliance observable in each round directly following an audit can the explained by the bomb-crater effect (Mittone, 2006).

We conclude that playing different music pieces with the aim of inducing different moods did not translate into different tax compliance levels. We only observed that individuals exposed to the positive mood condition (or Mozart's "Sonata for Two Pianos in D Major, KV 448") paid more taxes than those in the control condition. We also ran another linear mixed model with the two mood scores as predictors and relative tax compliance as outcome variable. Neither the positive valence score $(b=-0.01, p=0.793)$ nor the negative valence score $(b=0.01, p=0.861)$ was significantly related to tax compliance.

Figure 3: Tax compliance by conditions and experimental rounds

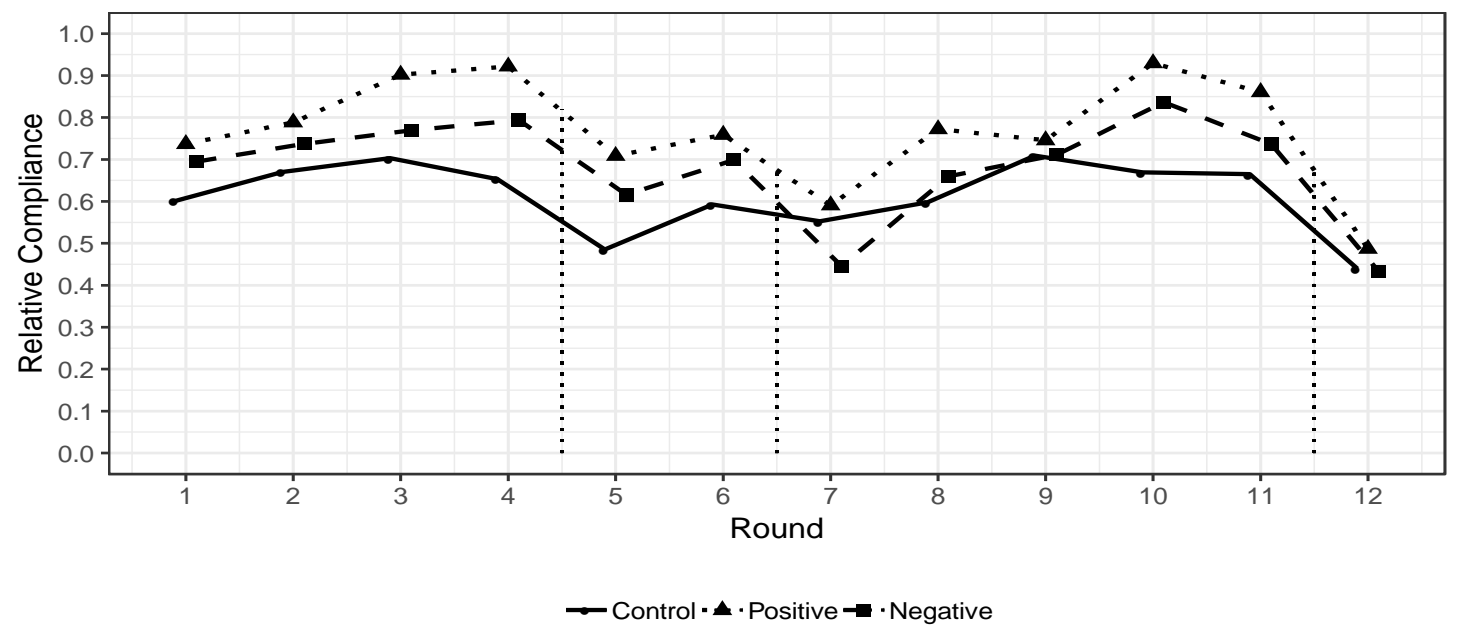

\subsection{Discussion}

Despite the success of using music to manipulate mood in previous studies, the intended manipulation was not successful in our study. One possibility is that the music manipulation might have been too subtle. By playing the music from the adjacent room and by not making it salient that the music was part of the experiment, participants might have tried to ignore the 
music instead of actively listening to it. Furthermore, the experiment itself might have evoked stronger emotions than the ones elicited by the music. It is possible that the slider task itself evoked increased stress levels, thereby overshadowing the influence of music in the background.

Not surprisingly, we do not find the expected effects of positive versus negative mood on tax compliance. However, we do find that music intended for a positive mood leads to higher compliance levels than in a control condition. One must interpret this result cautiously, given the manipulation check was not successful. One potential interpretation could be that

participants might have been less distracted in the control condition and have therefore might have taken the risky but rational decision to evade taxes.

To successfully investigate the influence of incidental emotions on tax compliance, we conclude from the current study that emotion inductions must be more intense. One approach would be to use videos that evoke strong emotions instead of (or combined with) music. Visual stimuli might be better suited and less subtle than merely playing background music.

\section{Empirical study (2): The role of integral emotions on tax compliance decisions}

While incidental emotions can arise from all kinds of circumstances, emotions integral to the tax context are direct consequences of tax authorities' actions. This suggests that tax authorities could use emotions as a tool, aiming their actions to elicit positive emotions by, for example, focusing on the provision of professional, friendly, and helpful services, or by eliciting trust in the authorities. These actions could reduce taxpayers' fear or anger when they are trying to solve filing issues, making communications more pleasant and potentially more effective. For instance, the tax authority in many countries has taken steps to improve the website and the online tax filing system. By the same token, when these are poorly designed, there is anecdotal evidence that these features are prone to elicit stress, frustration, and anger. In the following sections we present an empirical study that investigates the aspects of the tax process that may elicit integral emotions, in an attempt to determine the relevance of emotions for tax compliance decisions.

\subsection{Empirical investigation}

Enachescu et al. (submitted) conducted a comprehensive study consisting of a qualitative focus group study, followed by an independent quantitative survey, in a large sample of Austrian taxpayers. The aim was to identify crucial tax-related situations and 
procedures that are susceptible to elicit emotions. The authors were interested both in making out instances in the process of taxation that elicit emotions and in the identification of the specific emotions that are evoked. The study also tested the association between these specific emotions and tax compliance intentions using an experimental online survey.

\subsection{Part one: Qualitative focus group study}

In a first step, Enachescu et al. (submitted) conducted a qualitative focus group study with employed taxpayers, self-employed taxpayers, and tax auditors, in order to identify taxrelated situations and procedures that elicit emotions and also to identify the specific and relevant emotions. The authors conducted seven focus groups with a total of 24 participants. Self-employed and employed taxpayers discussed the bureaucratic procedures that are necessary to comply with tax obligations, along with their feelings when they go through the procedures of paying taxes. Tax auditors participated in separate focus groups to learn more about the auditing process and taxpayers' emotions during an audit from an outside perspective.

In Austria, self-employed and employed taxpayers go through different tax procedures. While self-employed taxpayers must declare income proactively, employees are subject to third-party reporting. These differences are reflected in the results: self-employed participants most frequently mentioned their tax advisors, whereas employed participants most often mentioned automatic tax withholding. General themes that emerged in both taxpayer groups were associating taxes with high work load, communicating with the tax authorities over unresolved questions, and reflecting about tax audits. The most relevant emotions evoked by these events were stress and anger for self-employed participants, and fear for employed participants. Nervousness, uncertainty, accused, guilt, anxiety, and frustration were mentioned in the range of negative emotions by both groups. Self-employed participants mentioned relief as the most prominent positive emotion, followed by feeling secure and happy. Employed participants most often mentioned surprise. Tax auditors reported mostly emotions such as nervousness, anger, frustration, and fear during tax audits (Enachescu et al., submitted).

\subsection{Part two: Quantitative survey study}

Based on these qualitative results, Enachescu et al. (submitted) developed an experimental survey to test the influence of emotions on intended tax behavior. First, they developed several tax scenarios meant to evoke emotions, and they also developed a comprehensive list of specific emotions. They hypothesized that participants experience 
different specific emotions depending on whether they have positive or negative experiences with tax authorities (e.g., communications, audit procedures). In turn, these emotions were assumed to influence intended tax behavior.

A sample of 523 Austrian taxpayers (employed and self-employed; representative for Austrian working population regarding gender and age) read a set of seven different taxrelated scenarios that described either positive or negative situations encountered during different taxpaying procedures (between-subject). Scenarios were slightly adapted to match differences in filing procedures between employed and self-employed taxpayers. After reading each scenario, participants completed an emotion questionnaire, indicating how they would feel in such a situation. The emotion questionnaire comprised a list of 19 specific emotions: accused, angry, annoyed, contented, dissatisfied, fearful, guilty, happy, helpless, hopeful, insecure, nervous, regretful, relieved, sad, secure, ashamed, stressed, and surprised.

The scenarios covered the following situations: (1) preparatory accounting tasks, (2) filing taxes, (3) contacting the tax authorities with a question, (4) receiving feedback from the tax authorities about a balance, (5) receiving an audit announcement, (6) experiencing an audit, and (7) evading taxes by claiming false deductions. Three of the seven scenarios (scenarios 3, 6, \& 7) were additionally followed by a short questionnaire assessing tax compliance intentions, asking the participants how likely they would make the following compliance decisions, after having experienced such a situation: paying taxes honestly, searching for loopholes to avoid taxes, evading taxes, or procrastinating in the decision. The 19 measured emotions for each scenario were clustered to four emotion groups using multidimensional scaling: emotions related to feelings of self-blame (e.g., shame \& guilt), anger-related emotions (e.g., angry \& annoyed), fear-related emotions (e.g., fear \& nervous), and positive emotions (e.g., happiness \& relief).

For compliance intentions, Enachescu et al. (submitted) found that tax compliance intentions are higher in the positive condition as compared to the negative condition in two of three scenarios ( $3 \&$ 6). Most importantly, this relationship was mediated by self-blame and anger-related emotions in these two scenarios. This means that a negative experience with the tax authorities elicits self-blame and anger, resulting in negative compliance consequences.

\subsection{Discussion}

The qualitative study of Enachescu et al. (submitted) provided insights into which emotions are relevant in various tax-related situations. The study allowed the authors to create 
research materials to systematically investigate the role of emotions in intended tax compliance decisions. The results revealed that, even though taxes might not be associated with emotions in the very first instance, taxpayers recall numerous emotional episodes when given the opportunity to reflect on these matters. Also, tax auditors reported to have observed many emotional reactions in taxpayers during the audits.

The survey study allowed further investigation of integral emotions. It revealed that these can best be described as self-blame, anger, fear, and general positive emotions. The key results were that experiencing anger-related emotions was associated with lower compliance intentions. Therefore, it is of utmost importance to take emotional experiences of taxpayers into consideration when designing taxation procedures in order to promote compliance.

\section{General discussion}

A large body of research demonstrates that human rationality is bounded and that decisions are by no means exclusively influenced by purely financial incentives (e.g., Kahneman, 2003). Emotional influences on judgment and decision making have received growing interest from the research community in recent years (Lerner et al., 2015). In the past, emotional influences have been viewed as a human fallacy hindering decision making (Loewenstein, Baumeister, \& Vohs, 2007). However, research shows that humans have ample difficulties in making "good" decisions once their emotional system is impaired, as exemplified by the famous case of Phineas Gage. Phineas Gage was an American railroad construction foreman who suffered from a frontal lobe lesion, a brain region associated with emotion processing, after a severe accident in which an iron rod was stuck through his skull. The accident caused dramatic changes in his personality, including the inability to experience emotions and to make rational decisions (Damasio, Grabowski, Frank, Galaburda, \& Damasio, 1994). Modern research presents evidence in both directions, emotional process as beneficial (Bechara \& Damasio, 2005) or hindering (Shiv, Loewenstein, Bechara, Damasio, \& Damasio, 2005) for decision making. Emotions are now believed to have adaptive functions that guide our attention to important aspects of the environment, that inform us rapidly about whether different options are better or worse for our well-being, and that help us develop a commitment to social norms (Pfister \& Böhm, 2008).

Research on emotions and decision making can be differentiated by whether research investigates either incidental or integral emotions, two types of emotions that are relevant for 
different contexts. Incidental emotions are elicited by surrounding circumstances such as background music in a shopping center. This type of emotional influence is important to consider when designing decision environments. Integral emotions are elicited by the decision situation itself, and it is important to consider this type of emotional influence when designing decision procedures.

The effect of incidental affect on decision making was first shown by Johnson and Tversky (1983), by investigating risk taking behavior under positive and negative mood. They found that participants perceive risks to be larger when induced with bad mood as compared to good mood. Fochman et al. (2019) found similar effects in an experimental study investigating the impact of incidental emotions on tax compliance behavior, using affective pictures to induce mood.

In this paper we presented a study using background music for mood induction, a method that might have been too subtle to yield the desired effects. The influence of incidental emotions on tax compliance is therefore still an open question that needs further investigation. Based on previous findings on incidental emotions and risk taking, as well as theoretical concepts such as the feeling as information approach, we can argue for hypotheses that lead in different directions. On the one hand, a bad mood signaling a problematic situation could foster systematic information processing, which should lead to more rational decisions guided by expected values, namely more tax evasion. On the other hand, a good mood could make optimistic evaluations more accessible, fostering risk taking, also leading to more tax evasion. Moreover, focusing on good versus bad mood can only be a first step into investigating the role of incidental affect. Research on specific incidental emotions, such as anger and fear, is also needed, as differential effects can be expected.

We also presented an additional study that investigated the effect of specific emotions elicited by the taxation context itself. As demonstrated by Enachescu et al. (submitted), many emotions are elicited in various tax-related situations. Results on the relationship between integral emotions and intended tax compliance behavior suggest that anger-related emotions are associated with higher intentions to evade taxes, a finding in line with results from consumer research (Bougie et al., 2003).

Tax compliance behavior has been investigated by economists, lawyers, and psychologists at least since the 1970s. How can these new findings on emotions and tax compliance be integrated in this well-established stream of research? Over a decade ago, psychological factors influencing tax compliance decisions were integrated into the existing 
research on economic factors, resulting in the "slippery slope framework" of Kirchler (2007) and Kirchler, Hoelzl, and Wahl (2008). We believe that emotions can be usefully introduced into this framework.

The slippery slope framework is a two-dimensional framework that distinguishes between the "power" of authorities and taxpayers" "trust" in the authorities. Power encompasses economic determinants to enforce compliance, predominantly audit probability, audit efficiency, and severity of fines, and power is defined by taxpayers' perception of authorities' capacity to detect and punish tax evaders. Trust integrates socio-psychological determinants of tax compliance. Trust results from taxpayers' understanding of tax law, from attitudes towards taxation and taxes, from the belief that the tax regulations are transparent, and from the belief that society accepts regulations and obeys the law (social norms). On the individual level, the framework differentiates between enforced compliance with tax law and voluntary compliance. The power of authorities is related to enforced compliance, while trust leads to voluntary compliance. On the aggregate level, the framework assumes that the exertion of strong power by the authorities fosters an antagonistic interaction climate, while trust yields a synergistic climate.

Empirical studies have generally confirmed the assumptions of the slippery slope framework (Kogler et al., 2013; Muehlbacher, Kirchler, \& Schwarzenberger, 2011). However, some studies come to inconclusive results regarding the effect of enforcement. While audit and fine rates are generally positively associated with tax compliance (Kirchler, Muehlbacher, Kastlunger, \& Wahl, 2007), some studies also find backfiring effects of audits on tax compliance (Beer, Kasper, Kirchler, \& Erard, 2015; Mendoza, Wielhouwer, \& Kirchler, 2017). A possible explanation for the observed negative effects of strict enforcement measures on compliance is that voluntary compliance can be eroded when honest taxpayers who are audited may feel falsely accused as criminals. This assumption is supported by results from an experimental survey study with self-employed taxpayers in Turkey (Olsen et al., 2018), who found that the exertion of power elevates the experience of negative as well as positive emotions. The authors interpret these results by saying that the exertion of power can be perceived positively and so can elicit positive emotions when taxpayers feel that they are protected from free-riders by these measures; further, in the case of well-targeted coercive power towards tax evaders, honest taxpayers may feel protected from being exploited, which is not the case if coercive power is used undifferentiated. Olsen et al. (2018) also suggest that the non-targeted exertion of power can evoke strong negative emotions, when honest taxpayers are subject to the same treatment as tax evaders. When honest taxpayers are audited 
and thereby treated as potential criminals, feelings of anger or fear are likely to be evoked. Anger has been shown to evoke retaliation behavior (e.g., Bougie et al., 2003), and will likely lead to deliberate decisions on whether it pays to evade or not. Tax avoidance and tax evasion are the likely reactions. In case of fear, taxpayers are likely to respond with avoidance measures, which can be legally justified. Taxpayers may also feel that they are forced to comply. Depending on whether coercive power is targeted or randomly wielded, taxpayers may therefore feel protected and generally positive, or they may instead become angry and react with fear.

In sum, the role of emotions in the slippery slope framework clearly needs further theoretical elaboration and empirical confirmation. Olsen et al. (2018) argue that the experience of negative emotions not only increases enforced tax compliance but also the intentions to evade taxes. They also argue that the relationship between power and emotions is moderated by trust perceptions; that is, when taxpayers perceive the tax authorities to be trustworthy, the negative effects of power are moderated and even reversed.

\section{Conclusions}

Emotions have increasingly gained attention in the decision-making research community. While economists have traditionally focused on rational processes in predicting choice, it is now becoming clear that emotional processes must also be considered in understanding behavior, especially tax compliance decisions by individual taxpayers. In this paper, we begin to dig into the sphere of emotions in taxation. We see that taxpayers are subject to emotional experiences that are evoked by taxation procedures, and we believe that similar effects can be observed for incidental emotions, as previous studies have suggested. However, more research is needed in order to better understand the power of emotions in this context.

Policy makers and tax authorities can profit from these insights by taking subjective experiences of taxpayers into account when designing taxation procedures. With our research we show that it is of ample importance to avoid causing frustration and anger when providing taxation services, and that it is worthwhile creating a confident atmosphere in which positive feelings can arise, in order to promote compliance.

\section{$\underline{\text { References }}$}


Allingham, M. G., \& Sandmo, A. (1972). Income tax evasion: A theoretical analysis. Journal of Public Economics, 1, 323-338.

Baumgartner, T., Esslen, M., \& Jäncke, L. (2006). From emotion perception to emotion experience: Emotions evoked by pictures and classical music. International Journal of Psychophysiology, 60, 34-43.

Bechara, A., \& Damasio, A. R. (2005). The somatic marker hypothesis: A neural theory of economic decision. Games and Economic Behavior, 52, 336-372.

Becker, G. S. (1962). Irrational behavior and economic theory. Journal of Political Economy, $70,1-13$.

Beer, S., Kasper, M., Kirchler, E., \& Erard, B. (2015). Audit impact study. Taxpayer advocate service annual report to Congress. Retrieved from

http://www.taxpayeradvocate.irs.gov/Media/Default/Documents/2015ARC/ARC15_Vol ume2_3-AuditImpact.pdf

Blaufus, K., Bob, J., Otto, P. E., \& Wolf, N. (2017). The effect of tax privacy on tax compliance-an experimental investigation. European Accounting Review, 26, 561-580.

Bosco, L., \& Mittone, L. (1997). Tax evasion and moral constraints: Some experimental evidence. Kyklos, 50, 297-324.

Bougie, R., Pieters, R., \& Zeelenberg, M. (2003). Angry customers don't come back, they get back: The experience and behavioral implications of anger and dissatisfaction in services. Journal of the Academy of Marketing Science, 31, 377-393.

Coricelli, G., Joffily, M., Montmarquette, C., \& Villeval, M. C. (2010). Cheating, emotions, and rationality: An experiment on tax evasion. Experimental Economics, 13, 226-247.

Damasio, H., Grabowski, T., Frank, R., Galaburda, A. M., \& Damasio, A. R. (1994). The return of Phineas Gage: Clues about the brain from the skull of a famous patient. Science, 264, 1102-1105.

Drouvelis, M., \& Grosskopf, B. (2016). The effects of induced emotions on pro-social behaviour. Journal of Public Economics, 134, 1-8.

Elster, J. (1998). Emotions and economic theory. Journal of Economic Literature, 36, 47-74.

Enachescu, J., Kogler, C., Olsen, J., Zeelenberg, M., Breugelmans, S. M., \& Kirchler, E. (submitted). The role of emotions in tax compliance behavior: A mixed-method apporach.

Erard, B., \& Feinstein, J. (1994). The role of moral sentiments in audit perceptions and tax compliance. Public Finance, 49, 70-89.

Fochmann, M., Hechtner, F., \& Mohr, P. N. C. (2019). When happy people make society unhappy: How incidental emotions affect compliance behavior (SSRN No. 3259071). Köln.

Forgas, J. P. (1995). Mood and judgment: The affect infusion model (AIM). Psychological Bulletin, 117, 39-66.

Garlin, F. V., \& Owen, K. (2006). Setting the tone with the tune: A meta-analytic review of the effects of background music in retail settings. Journal of Business Research, 59, 755764. 
Gill, D., \& Prowse, V. (2012). A structural analysis of disappointment aversion in a real effort competition. American Economic Review, 102, 469-503.

Grasmick, H. G., \& Bursik, R. J. J. (1990). Conscience, siginificant others, and rational choice: Extending the deterrence model. Law \& Society Review, 24, 837-862.

Johnson, E. J., \& Tversky, A. (1983). Affect, generalization, and the perception of risk. Journal of Personality and Social Psychology, 45, 20-31.

Kahneman, D. (2003). A perspective on judgment and choice: mapping bounded rationality. The American Psychologist, 58, 697-720.

Kämpfe, J., Sedlmeier, P., \& Renkewitz, F. (2011). The impact of background music on adult listeners: A meta-analysis. Psychology of Music, 39, 424-448.

Kastlunger, B., Muehlbacher, S., Kirchler, E., \& Mittone, L. (2011). What goes around comes around? Experimental evidence of the effect of rewards on tax compliance. Public Finance Review, 39, 150-167.

Kirchler, E. (2007). The economic psychology of tax behavior. Cambridge: Cambridge University Press.

Kirchler, E., Hoelzl, E., \& Wahl, I. (2008). Enforced versus voluntary tax compliance: The "slippery slope" framework. Journal of Economic Psychology, 29, 210-225.

Kirchler, E., Muehlbacher, S., Kastlunger, S., \& Wahl, I. (2007). Why pay taxes? A review of tax compliance decisions. International Studies Program. Retrieved from http://aysps.gsu.edu/isp/files/ispwp0730.pdf

Kogler, C., Batrancea, L., Nichita, A., Pantya, J., Belianin, A., \& Kirchler, E. (2013). Trust and power as determinants of tax compliance: Testing the assumptions of the slippery slope framework in Austria, Hungary, Romania and Russia. Journal of Economic Psychology, 34, 169-180.

Lerner, J. S., \& Keltner, D. (2000). Beyond valence: Toward a model of emotion-specific influences on judgement and choice. Cognition \& Emotion, 14, 473-493.

Lerner, J. S., Li, Y., Valdesolo, P., \& Kassam, K. S. (2015). Emotion and decision making. Annual Review of Psychology, 66, 799-823.

Loewenstein, G. (2000). Emotions in economic theory and economic behavior. American Economic Review, 90, 256-260.

Loewenstein, G., Baumeister, R. F., \& Vohs, K. D. (2007). Do Emotions Help or Hurt Decisionmaking: A Hedgefoxian Perspective. New York: Russell Sage Foundation. Retrieved from http://search-ebscohostcom.uaccess.univie.ac.at $/$ login. aspx $?$ direct $=$ true $\& d b=$ nlebk $\& A N=1069881 \&$ site $=$ ehost live.

Loewenstein, G., \& Lerner, J. S. (2003). The Role of Affect in Decision Making. In R. J. Davidson, H. H. Goldsmith, \& K. R. Scherer (Eds.), Handbook of Affective Science (pp. 619-642). Oxford, England: Oxford University Press.

Martin, M. (1990). On the induction of mood. Clinical Psychology Review, 10, 669-697.

Mendoza, J. P., Wielhouwer, J. L., \& Kirchler, E. (2017). The backfiring effect of auditing on tax compliance. Journal of Economic Psychology, 62, 284-294. 
Mittone, L. (2006). Dynamic behaviour in tax evasion: An experimental approach. Journal of Socio-Economics, 35, 813-835.

Muehlbacher, S., Kirchler, E., \& Schwarzenberger, H. (2011). Voluntary versus enforced tax compliance: Empirical evidence for the "slippery slope" framework. European Journal of Law and Economics, 32, 89-97.

Murphy, K., \& Tyler, T. R. (2008). Procedural justice and compliance behaviour: The mediating role of emotions. European Journal of Social Psychology, 38, 652-668.

Olsen, J., Kasper, M., Enachescu, J., Benk, S., Budak, T., \& Kirchler, E. (2018). Emotions and tax compliance among small business owners: An experimental survey. International Review of Law \& Economics, 56, 42-52.

Pfister, H.-R., \& Böhm, G. (2008). The multiplicity of emotions: A framework of emotional functions in decision making. Judgment and Decision Making, 3, 5-17.

Russell, J. A., \& Barrett, L. F. (1999). Core affect, prototypical emotional episodes, and other things called emotion: dissecting the elephant. Journal of Personality and Social Psychology, 76, 805-819.

Sacharin, V., Schlegel, K., \& Scherer, K. R. (2012). Geneva emotion wheel rating study. Geneva. Retrieved from https://archive-ouverte.unige.ch/unige:97849.

Scherer, K. R. (2005). What are emotions? And how can they be measured? Social Science Information, 44, 695-729.

Schwarz, N. (2012). Feelings-as-information theory. Handbook of Theories of Social Psychology: Volume 1, 289-308.

Shiv, B., Loewenstein, G., Bechara, A., Damasio, H., \& Damasio, A. R. (2005). Investment behavior and the negative side of emotion. Psychological Science: A Journal of the American Psychological Society / APS, 16, 435-439.

Srinivasan, T. N. (1973). Tax Evasion: A model. Journal of Public Economics, 2, 339-346.

Thompson, W. F., Schellenberg, E. G., \& Husain, G. (2001). Arousal, mood, and the Mozart effect. Psychological Science, 12, 248-251.

van de Ven, N., \& Zeelenberg, M. (2011). Regret aversion and the reluctance to exchange lottery tickets,. Journal of Economic Psychology, 32, 194-200.

Watson, D., Clark, L. A., \& Tellegen, A. (1988). Development and validation of brief measures of positive and negative affect: the PANAS scales. Journal of Personality and Social Psychology, 54, 1063-1070.

White, E. L., \& Rickard, N. S. (2016). Emotion response and regulation to "happy" and "sad" music stimuli: Partial synchronization of subjective and physiological responses. Musicae Scientiae, 20, 11-25.

Zeelenberg, M., \& Pieters, R. (2006). Feeling is for doing: A pragmatic approach to the study of emotions in economic behavior. In D. De Cremer, M. Zeelenberg, \& K. Murnighan (Eds.), Social psychology and economics (pp. 117-137). New York: Psychology Press. 